\title{
Graphics Software Application in Product Design Teaching
}

\author{
Fan Minda ${ }^{1, a^{*}}$, Huang Junhua ${ }^{2, b}$, \\ ${ }^{1}$ Foshan University, Jiangwan yi road No.18,Chancheng district, Foshan city, Guangdong province, \\ China \\ ${ }^{2}$ Guangzhou academy of fine arts, Guangzhou university city west road no.168,Panyu district, \\ Guangzhou, Guangdong province, China \\ aemail:xieliaosha@126.com, bemail:150340090@qq.com,
}

Keywords: Graphic Software ;Product design teaching; Application

\begin{abstract}
Computer graphics technology has been developed since several decades ago, and now, many excellent graphics software have been applied to each stage of design. Compared with the traditional freehand performance, the effect shown on the graphics software is extremely realistic. However, it also is provided with inherent disadvantages, such as high requirements for software, and slow speed, etc. Product design teaching includes many design contents, which comprises market research, user research, draft disposal, scheme adjustment, final decision of scheme and other stages, while each stage is different in task and different graphics software will also be applied to it. With the development of technology, teaching contents of new graphics software joining are also required to be updated in real-time. Packaging of graphics software of different professional directions and reasonable distribution of teaching resources in accordance with software attributes will be the new form for computer aided design teaching.
\end{abstract}

\section{Basic contents of computer aided design}

Influences of computer graphics software on design. Today, the design process completed by using computer as the tool is called as “computer aided design”. During the process, the most distinct technical features-computer, graphics and information are shown. Such design methods have been quite mature, Product Designer works based on computer graphics and plans the whole life cycle of products.

Computer graphic means the form shown on displayer and transferred from two-dimensional or three-dimensional graphic by computer through mathematical algorithm. In computer graphics, form means the graphic shown on displayer and the video composed of graphics. For its depending on the displayer and graphics card with dynamic display, computer graphics can be flexible in displaying different graphics and videos of different contents. Compared with the traditional paper media, computer graphics technology can be used to transmit information quickly, correctly and clearly. And at present, various kinds of computers and mobile internet are combined, which completely changes people's lifestyles and thinking habits. And at the same time, it even also overpasses the scope of serving a person, and widely influences all aspects of society such as politics, economics, traffic, environment and production, etc., thus playing an important role in controlling life of people and development of society in technology.

Characteristics of computer graphic performance. Compared with the traditional freehand graphic performance, computer graphic is provided with many advantages such as more realistic effects, convenience for modification and management. After user demands and market positioning are determined, product design will then enter the proposal stage. However, before computer aided design appears, in most cases, product design is expressed by free-hand painting. Skilled designer can express the details of scheme correctly in short time. But with the further development of design process, at form adjustment and color mechanism expression, free-hand painting by using traditional tools will show its disadvantages which are mainly shown in form adjustment and effect expression. Erasing or redraw will be required for adjustment on the basis of paper painting in most cases. While 
modification can be conducted on targeted parts on the basis of completed painting in painting by computer, with each line accurately controlled. In representing color and mechanism, traditional painting can be used to realize a comparative effect only, and can not represent the visual perception in real environment. While on the support of computer in modeling and rendering software, scheme's color and mechanism can be presented quite truly, with little differences between its expression effects and the visual effects in real environment. Besides, planar processing software such as Photoshop, Illustrator, etc. can also be used to complete typesetting \& editing and display painted form on the basis of graphics. Besides it can be used to present scheme in three-dimensional form, modeling software can also be combined with various rapid prototyping technology to present scheme in real entity.

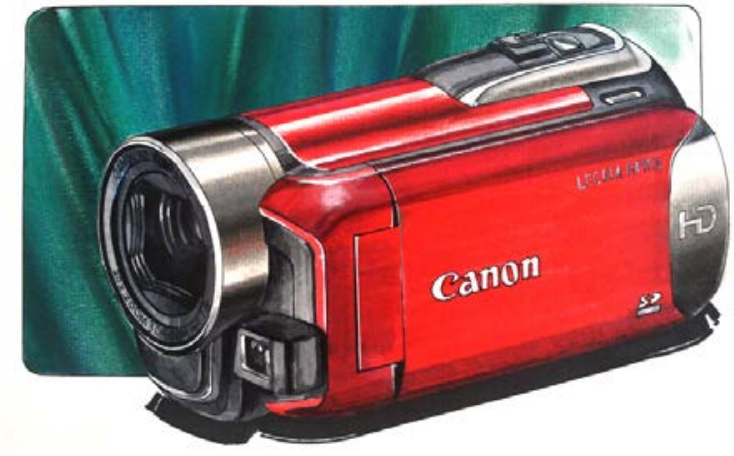

Fig. 1, Hand-painted performance

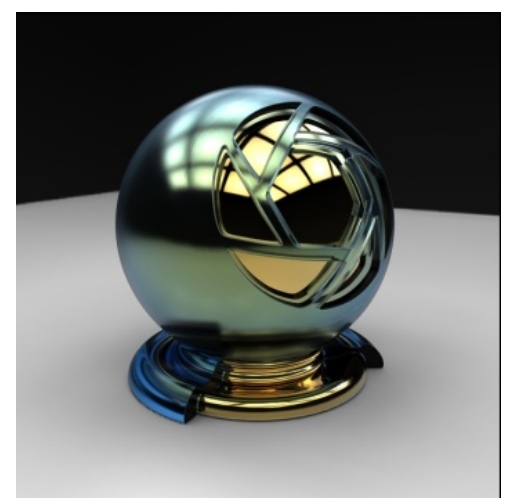

Fig.2, Computer rendering

Nowadays, computer aided design has become the basic means of product design. However, it also has many disadvantages compared with the traditional expression by hands. For example, its cost efficiency rate is lower than that of paper painting. Computer expression shall be completed only on the support of computer hardware and software, with a higher requirement for drawing conditions, while the traditional freehand painting can be completed only by paper and pens. Longer time shall be required for computer expression, for example, effect sketch will be expressed by three-dimensional modeling and rendering, and computer painting can be completed and adjusted by pressing switching tools. These operations will influence expression speed. Besides, lack of "hand touch" also exists in computer painting. Some hardware manufacturers with brands such as Wacom, Hanvon, surface, etc., are also dedicated in developing corresponding products to make up for the defect. Paperless painting time will be inevitable with the development of technology, but at present, paper painting can not be substituted completely. Today, the most efficient way is to combine free-hand painting with computer painting. At earlier stage, paper painting for sketch is used, and at later stage, it will be translated into digital image by scanner, and then be further edited and modified. It can be seen that painting is in the alteration period of old and new technologies.

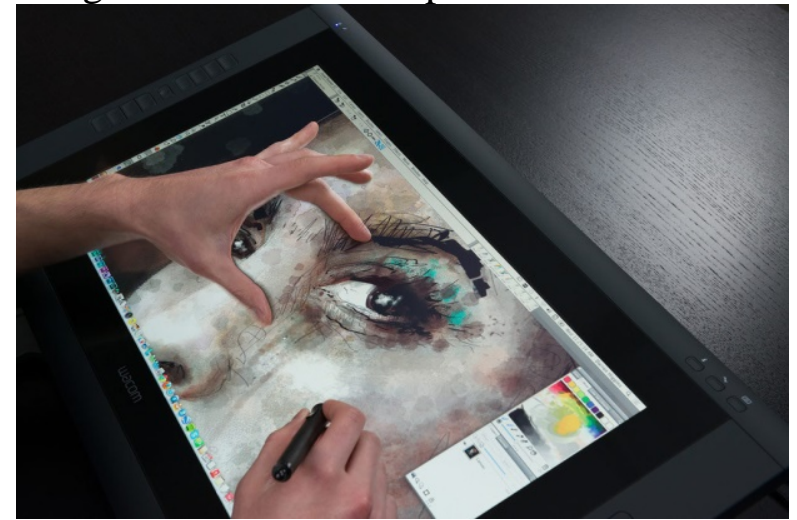

Fig.3, Screen painting products of Wacom

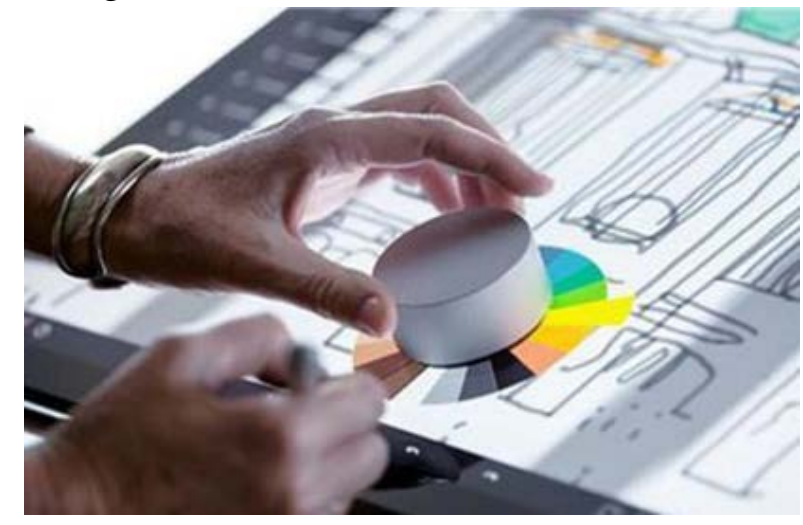

Fig.4, Surface studio and its auxiliary human-computer interaction module 


\begin{tabular}{|l|l|l|}
\hline \multicolumn{1}{|c|}{ Content } & Paper painting by hands & \multicolumn{1}{c|}{ Computer expression } \\
\hline Hardware & Paper, pen & Computer, software, digital panel, power supply \\
\hline Speed & Fast & Slow \\
\hline $\begin{array}{l}\text { Hand } \\
\text { touch }\end{array}$ & Good & Poor \\
\hline Effect & So-so & Excellent \\
\hline
\end{tabular}

Table 1 Advantage \& disadvantage comparisons between freehand painting and computer painting

\begin{tabular}{|l|l|l|}
\hline Content & Time for paper painting & \multicolumn{1}{c|}{ Time for computer painting } \\
\hline Typesetting & $5[\mathrm{~min}]$ & $2[\mathrm{~min}]$ \\
\hline $\begin{array}{l}\text { Line } \\
\text { drawing }\end{array}$ & $10[\mathrm{~min}]$ & $25[\mathrm{~min}]$ \\
\hline Adjustment & $10[\mathrm{~min}]$ & $5[\mathrm{~min}]$ \\
\hline $\begin{array}{l}\text { Colorizatio } \\
\mathrm{n}\end{array}$ & $15[\mathrm{~min}]$ & $30[\mathrm{~min}]$ \\
\hline Total & $40[\mathrm{~min}]$ & $62[\mathrm{~min}]$ \\
\hline
\end{tabular}

Table 2 Comparison of time for author (generally skilled) in freehand painting and computer painting at each stage

\section{Combination of product design teaching and graphics software}

Teaching situations of fundamental graphics design software. Product design specialty reflects the expression technologies of other design disciplines comprehensively. In teaching, students are not only required to be provided with planar expression skills of computer, but also with three-dimensional representation skill. Research object of product design is monomer product, and students need to design each detail and structure of product in three-dimensional space, therefore, three-dimensional modeling software is included in the software taught. Such software mainly includes facet modeling software Rhino, and 3D max, etc., as well as solid modeling software Solidworks, Pro-E, etc. In teaching rendering software, 3D max render owned by itself is taught firstly, followed by vary render. These two kinds of renders both belong to render in common use, which can complete space rendering and monomer rendering. With the development of computer graphics technology, special render aimed at product design appears. And teaching contents of computer rendering also change correspondingly. Teaching of special render of product ranges from Hyper short at first to the most popular Keyshot at present, showing that technology improvement promotes the renovation of teaching contents.

Application of graphics design software at each teaching stage. Main content of product design teaching is subject project for promoting students' comprehensive applications of each design skill. In general, subject design project will be set with a proposition which can be a real topic or a virtual topic. Real topic aims at the real object of design service with certain market value required to be produced. Such topic is provided by social institutions generally, and the most common form is design and development entrusted by brand enterprise. In real topic, students can join in team with focus on completing user analysis and creative scheme the two links. In later period, adjustment will be made correspondingly after combining production situations \& market demands and communicating with designer of enterprise. While virtual topic is the subject project determined in accordance with existing social demands and design concepts. And such topic will be relatively targeted, can train students' design thinking in a certain direction and be available for carrying the study of sociology. The biggest advantage of virtual subject is that the process can be freely controlled, giving deep guidance to weak links of students. Therefore, the subject developed for product design teaching focuses on virtual topic generally, with real topic training developed for coordinating with different social institutions at the same time. Real topic and virtual topic will be carried out in the same procedure, but will produce different class-ending achievements due to different focuses. Different computer graphics technologies will be applied at different stages of subject, and below shall be illustrations of contents at each stage and software application respectively. 
Investigation. The investigation of product design is divided into the several parts like user study, analysis for competitive product, market positioning, field investigation and process investigation. On the product design teaching, the students are mainly required to accomplish the two parts-user study and analysis for competitive product. On the user study, the students will aim at the user's usage mode of the product in different environment to carry out investigation, know the user's usage habit and discover the defect of the existing product. This study emphasizes on looking for the user's demand point (pain point). On the analysis for competitive product, the students will look for the information of the like product, which includes functional characteristics, material property and price of the similar product and whether the use defect exists in it. The graphic software of computer is used rather low on this stage, which is only used in organizing the investigation data and information mutual communication. The common form is to use the plane software to typeset the data and establish analysis model (mind map) and then PPT and other software are used to carry out exhibition and mutual communication. At present, the similar graphic software applied in other fields has also been rather conventional.

Initial stage of proposal. After the investigation, the students shall develop the targeted design in accordance with the investigation conclusion. Usually the students need to propose several design concepts aimed at one user demand point. These design concepts are usually incomplete, which need to be adjusted based on this. Hence, the performance technology used shall have the characteristics easy to control and convenient to modify. As stated before, there is the problem difficult to modify in the form of bare-handed drawing. At present, the graphic software widely referenced on this stage is mainly the sketch book series software produced by Autodesk. The software of this series is simple and easy to use and can provide various brush tools where the sketch book Designer version can run with the help of PC platform. The most important characteristic of this version is that each line drawn all is vectograph, hence, all can be edited at the second time. The user can draw several probable lines first and then adjust each line. The version greatly promotes the user's drawing quality. The most important characteristic of sketchbook pro version is that it provides the abundant brush tools and can draw freely. Different brushes can simulate different brushwork. Besides carrying out the drawing of the designing scheme, this version can also carry out other artistic creations. Because it can run with the help of tablet PC, this version can also draw at any time and at any place. However, on this stage, the designer who has skillfully mastered the drawing skills is often more accustomed to paper drawing.

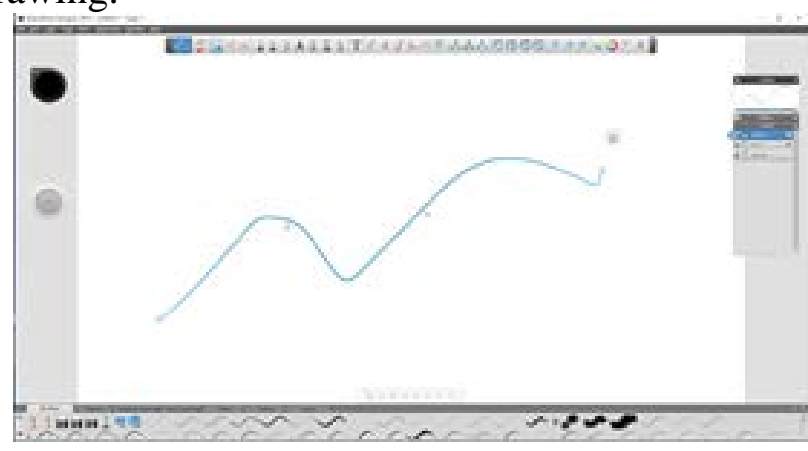

Fig.5 The line can be edit in Sketchbook Designer

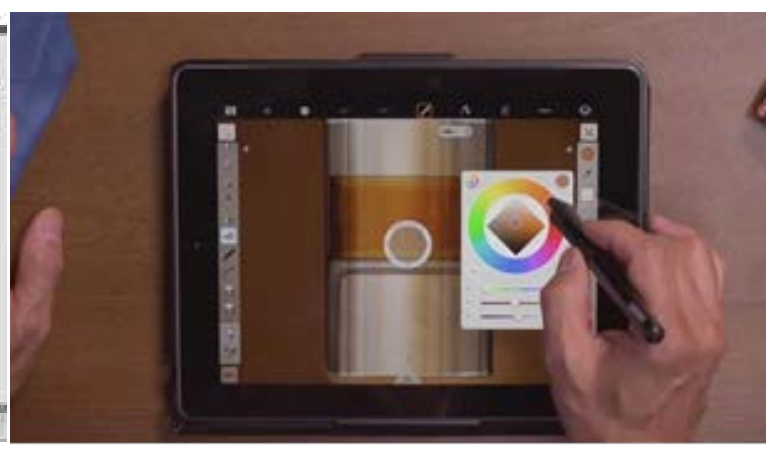

Fig.6 Use the tablet PC to draw

Final decision of the proposal. The design of product structure, material, mechanism and color are still lacking in the initial stage of proposal, which needs to be expressed with the help of graphic technology and rapid proto-typing technology. This stage is accomplished mainly based on the digital model. The modeling software generating the digital model is divided into two modes-patch modeling and solid modeling where the patch modeling utilizes Nurbs curve to build the model frame in the space and adds the path to form the digital model based on the frame. The digital model formed is the hollow model. This kind of software can rapidly accomplish the modeling of the complex organic form but the operational error is easy to occur on the treatment of the model detail. Moreover, the hollow model can not be adjusted at a second time, either. This kind of software has Rhino, 3D Max and so on; the solid modeling software adopts the solid model algorithm and the user can utilize 
the coordinate to build a solid data model in the three-dimensional space. The characteristic of the solid model is that it can change the form by adjusting the data and deal with the operational error that barely exists on the detail treatment. However, its defect is that it is very difficult to build the organism with complex form. This kind of software has Solidworks, Pro-E, UG and so on. On the model rendering, the renderer that is adopted in the product design field has Keyshot, Showcase and so on where Keyshot renderer is one of the most popular in product rendering. No matter whether it is in the top design of the enterprise or the teaching field, Keyshot can meet demand from various designers, which lies in its simple, audio-visual and friendly interface design. Compared to renderers like Vary and so on, the most important advantage of Keyshot is that it provides the default material library and light map library. The user does not need to set the material parameter to directly apply the existing material. Moreover, with the promotion of the version, the number of its material becomes gradually abundant. The present version can already fully meet the user's demand. In addition, the angle control of the camera and animation rendering can be both extremely convenient, too.

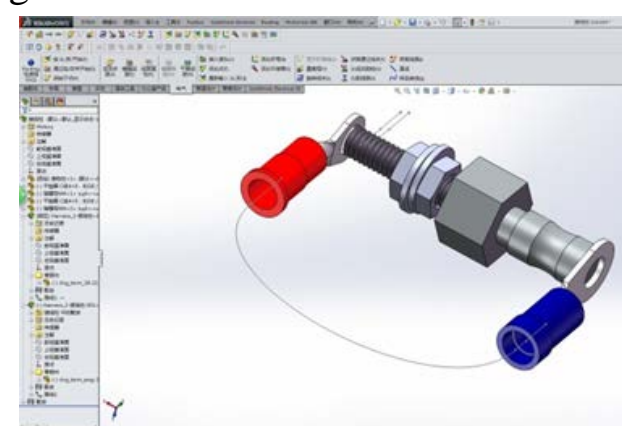

Fig.7 Solidworks modeling interface

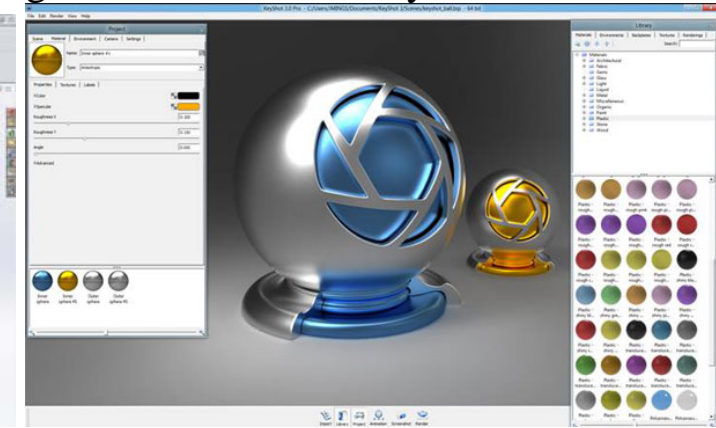

Fig.8 Keyshot material library

\begin{tabular}{|l|l|l|}
\hline \multicolumn{1}{|c|}{ Content } & \multicolumn{1}{|c|}{ Software used } & \multicolumn{1}{c|}{ Task } \\
\hline $\begin{array}{l}\text { Design } \\
\text { investigation }\end{array}$ & Movie maker、Mindmanager、Photoshop & $\begin{array}{l}\text { Accomplish the user's investigation and market } \\
\text { analysis and look for user's demand point. }\end{array}$ \\
\hline $\begin{array}{l}\text { Initial stage of } \\
\text { proposal }\end{array}$ & $\begin{array}{l}\text { Sketchbook series, Conceptional drawing } \\
\text { board, Sketches Pro and Photoshop }\end{array}$ & $\begin{array}{l}\text { Draw the concept, adjust the scheme and perfect the } \\
\text { detail }\end{array}$ \\
\hline $\begin{array}{l}\text { Final decision } \\
\text { of the proposal }\end{array}$ & $\begin{array}{l}\text { Rhino、3D Max、Solidworks、Pro-E、 } \\
\text { UG、AE、Keyshot、Showcase、Alias、 } \\
\text { Autocad }\end{array}$ & $\begin{array}{l}\text { Confirm the detail, structure, modeling, form and } \\
\text { color and make the design sketch and model. }\end{array}$ \\
\hline
\end{tabular}

Table 3 Task and software usage in each stage of the subject

\section{New form of design teaching based on software package}

With the designing graphic software more widely applied, the whole process of the product design teaching will be more attached on graphic software. At present, the software in each stage of teaching can absolutely be packed to form the same series of teaching software package. This software package can include mind map software like Mindmanager, plane design software like Photoshop, drawing software like sketchbook series, modeling software like Solidworks and rendering software like Keyshot. Meanwhile this software can combine the content in accordance with the different major fields and can build the teaching resource allocation based on software package on teaching. The allocation can be divided into general software teaching and special software teaching. The students with different major field can learn the general software in a merged class. With respect to the independent teaching form in each major, this will greatly save the time. In addition, the usage of the same software makes it more convenient for course management and makes the communication smoother among students or between students and teachers.

\section{Acknowledgements}

This work was financially supported by the 2016 Foshan science and technology innovation platform project "Industrial Design Innovation Public Service Platform Construction" (Project number: 2016 AG100321), 2015 Foshan development of economic science and technology industrial 
design projects "Industrial Design Platform of International Cooperation" (Focaigong [2015] no. 2015), 2013 Foshan technology bureau of science and technology development special fund project "The New Light Source Product Development and Public Service Platform" (Project number: 2013 HZ100012)

\section{References}

[1] Yi Xiqiong, He Fengmei: Teaching Model and Strategy of Computer Aided Industrial Design (Furniture \& Interior Design, China 2015.12)

[2] Shan Zeng ,YaJun Li: Ideas on the Teaching of Product Design Basic Courses(2009 IEEE 10th International Conference on Computer-Aided Industrial Design \& Conceptual Design,China2009.1)

[3] Yu Xiangkuang :Problems and Solutions on the Teaching of Computer-aided Industrial design(The 9th International Conference on Computer-Aided Industrial Design \& Conceptual Design(CAID\&CD'2008),China 2008.1)

[4] Andy S.J. Zhang : Teaching Computer Aided Product Design With Aesthetic Considerations (25th Computers and Information in Engineering Conference:(DETC2005) vol.3 pt.A,USA,2005.1)

[5] Abler R.T.,Owen H.L.,Riley G.F: University methodology for internetworking principles and design projects(IEEE Transactions on Education,2003)

[6] Amal Oraifige Mian Wu Barry Mills Ilias Oraifige:An online intelligent system for teaching design technologies to engineering students(Engineering Education,2011.6) 